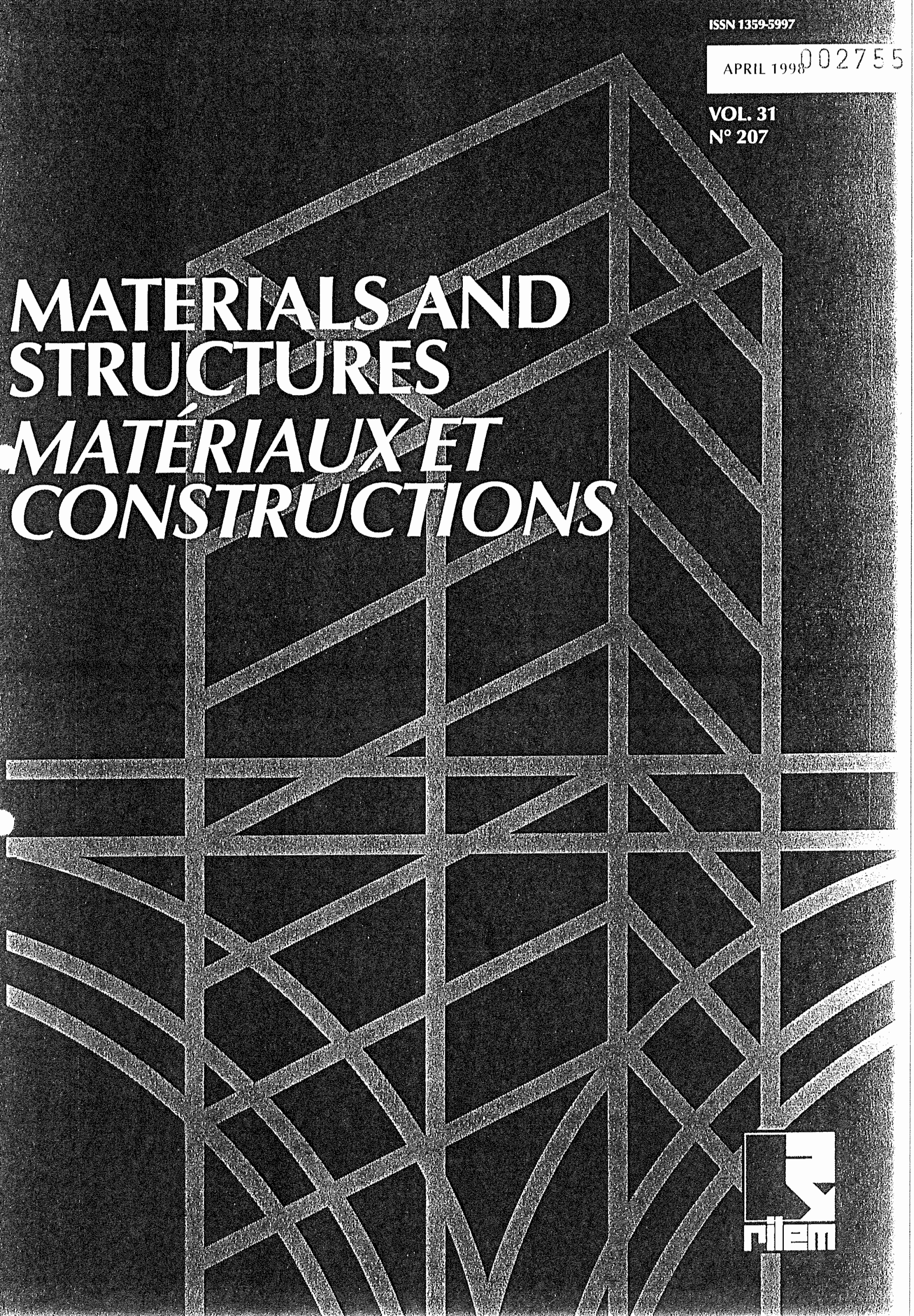




\title{
Characterization of unidirectional carbon fibre reinforced plastic laminates
}

\author{
Masoud Motavalli and Peter Flüeler \\ Swiss Federal Laboratories for Materials Testing and Research (EMPA), CH-8600 Dübendorf, Switzerland
}

\section{ABSTRACT}

The purpose of the present paper is to outline a set of recommended tests in order to characterize the behavior of carbon fibre reinforced plastic laminates. The tests outlined in this contribution are classification of visual defects, dimension and density, fibre and resin content, tensile strength, apparent interlaminar shear strength, in-plane shear modulus, dynamic torsion property, static bending property, dynamic bending property, and thermal expansion coefficient.

As a selected example, results of two tensile tests on CFRP laminates are reported.

\section{BACKGROUND AND INTRODUCTION}

Structural post-strengthening is required when structures experience new conditions including load increases, load redistributions, and damages occurred due to normal usage or environmental factors. Investigations on the bonded steel plate strengthening at the Swiss Federal Laboratories for Materials Testing and Research (EMPA) have shown that long-term problems concerning corrosion behavior must be expected in the outdoor applications. For this reason and due to other considerations, steel plates were replaced by CFRP laminates. Consequently, CFRP laminates were employed for post-strengthening purposes in a variety of applications. The CFRP laminates are manufactured using a pultrusion process. Pultrusion has been practiced for over 40 years [1]. The pultrusion principle is accompanied with a continuous press. Normally, 12000 parallel filaments are pulled through an impregnated bath; thereafter they are formed into laminates under heat and cured. These laminates are unidirectional, i.e. the fibres in the laminate run only in one direction. Correspondingly, the laminate strength in the fibre direction is proportional to the fibre strength, and therefore is very high compared to the transverse direction.

During the years 1984 to 1989 , CFRP laminates were successfully employed for the first time at EMPA for post strengthening of concrete beams [2]. A 80 meter long prestressed bridge with a partial reinforcement of CFRP laminates was realized in Ludwigshafen in 1991 for the first time [3]. In 1994, a method was developed at EMPA to strengthen masonry shear walls in seismically active regions with CFRP laminates [4]. In 1997, the behavior of an aluminum box beam reinforced with CFRP laminates was investigated. The structure was subjected to a temperature change of $100^{\circ} \mathrm{C}[5]$. Prior to design and application of a post-strengthening with CFRP laminate, the behavior of the strengthening laminate should first be characterized. The purpose of the present paper is to establish a list of recommended tests in order to characterize the behavior of CFRP laminates. Such a list may help the structural engineer to choose the necessary tests for designing the laminates for post-strengthening and for the purpose of quality control of the product.

\section{TEST METHODS}

The most common standardized tests for the CFRP laminates may be divided into the two following categories (Cat.):

Cat. 1: Tests which are recommended for the first serics of a newly developed laminate.

Cat. 2: Tests which are recommended for quality control.

\section{Cat. 1 and Cat. 2: Classifying of visual defects (ASTM D2563)}

This is a visual inspection in order to specify and classify the possible defects. Visual inspection should result in description of surface cracks and description of imperfections such as interply delamination, delamination by improper machining, alignment of fibres, dry spot, foreign inclusion, fractures, lack of fillout, porosity, etc.

\section{Cat. 1 and Cat. 2: Dimensions and density (DIN 29971)}

This test method covers the determination of dimensions as well as mass per unit area of the CFRP laminates.

\section{Cat. 1 and Cat. 2: Fibre and resin content (ASTM D3171-76 and DIN EN 2564)}

This test method covers the determination of the fibre content of CFRP laminates. The technique used is based on the dissolution of the matrix resin by a liquid medium, which does not attack the fibres.

\section{Cat. 1 and Cat. 2: Tensile Tests (ASTM D3039 and DIN EN 2561)}

This test method determines the in-plane tensile properties of CFRP laminates parallel and perpendicular to the fibre direction (see Fig. 1). Tensile tests require 


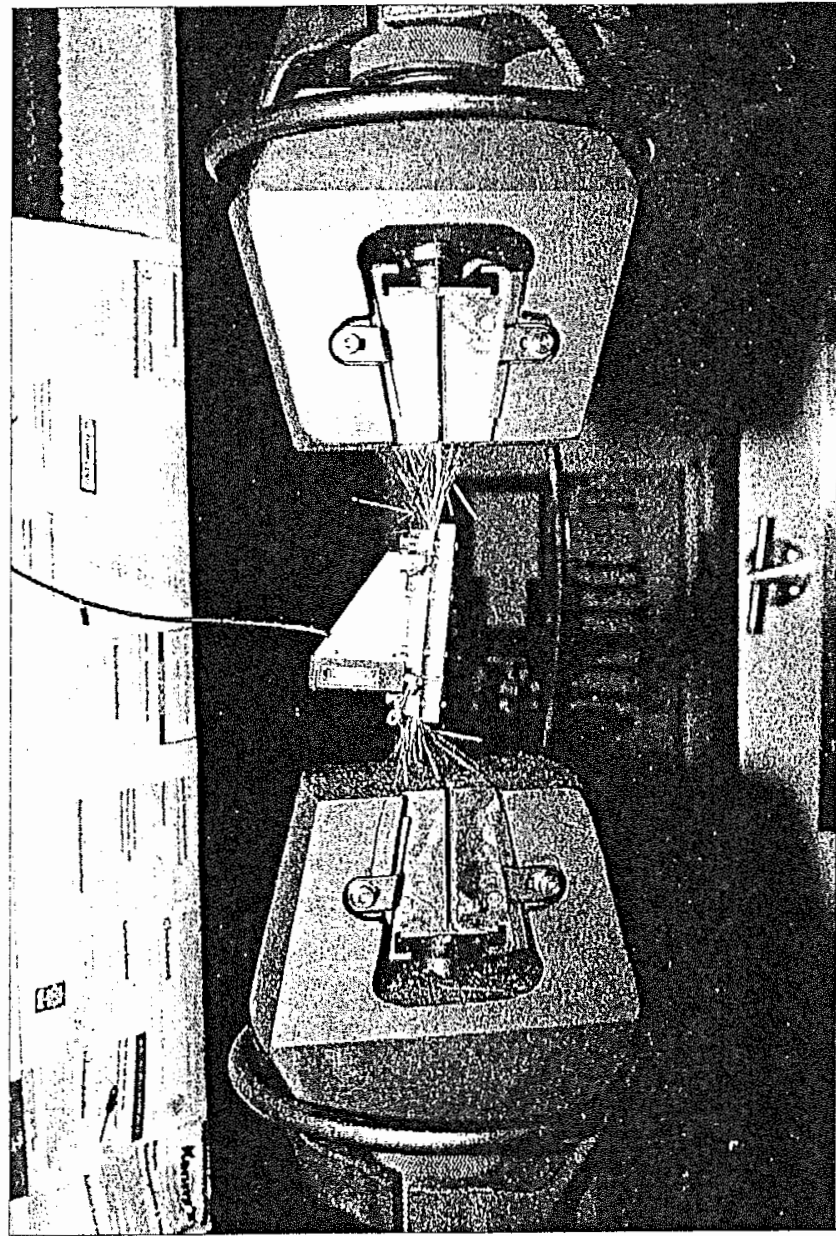

Fig. 1 - A unidirectional CFRP laminate after tensile test. This figure also shows an extensiometer, which is installed in order to determine the in-plane tensile properties of the laminate.

appropriate measuring techniques for determining the strain. Accurate strain acquisition an be achiced by strain gatuges or by precision extensiometers. For cxermely low strain. optical incerferometers are used. Care should be taken in providing proper axill alignmont of the test specimems.

\section{Cat. 1: Apparent interlaminar shear strength (ASTM D2344 and DIN EN 2563)}

This test method covers the decommintmon of the apparcent incerlaminar shear strengeh of CFRl' lanninates by the short-beam bending resc nicthod. For (.FRP' ham-

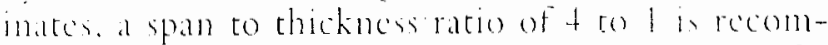
mended. The apparene shear serengeh can be nebed for compuracive testmes of C.FRP lammates, it all tallures are in herizontal shcirs.

\section{Cat. 1: In-plane shear modulus [6]}

In this method, in-planc shair nodulus of CFRP haninates is determined by the anticlastic plate bending method. Furthermore, the in-plane Poissons ratio con also be determined by this method.

\section{Cat. 1: Dynamic torsion property (ASTM D5279 and DIN 53445)}

This test method provides interlaminar shear modulus as a funcrion of temperature for unidirectional reinforced CFRP laminates using forced-vibration technicuucs. Plots of the elastic (storage), loss (viscous), and complex moduli and damping can bx obtained as a function of frequency, time or temperature.

\section{Cat. 1: Static bending property (ASTM D790 and DIN EN 2562)}

The bending properties of CFRP laminates can be determined using a three point or a four point test setup. The span to thickness ratio is usually about 35 .

\section{Cat. 1: Dynamic bending property (DIN 53440)}

This test method covers the determination of the chastic bending propertics of CFRP lanninates by resonance tcsting of a cantilever beam. The resonance frequency can be tuned by a resenator at the free end of the bram.

\section{Cat. 1: Thermal expansion coefficient (ASTM D696-91 and DIN 53752)}

This test method covers the determination of the coefficient of linear thermal expansion of CFRP lanninates - parallel and perpendicular to the fibre direction by the use of a dilatoneter. Determination of the thermal expansion should exclude changes in length due to changes in moisture content, curing, loss of plasticizer or solvents, release of stresses, phase changes and other factors. In general, this would not be completely possible Therefore, this test method provides an approximation for the true thermal expansion.

\section{EXAMPLES OF TENSILE TESTS: RESUITS AND DISCUSSION}

As a specific example of tinsile testing, Fig. 2 illustrates the tensile stress-strain curve of a CFRP lanminate botls parallel and perpendicular to the fibre direction. It show's that the tensile strength perpendicular to the fibre draction is only $3 \%$ of the tensile strengrth parallel to the fibres. The elasticity modulus perpendicular to the filme dircetion is almost $7^{\prime \prime} / \mathrm{h}$ of enc clasticity modulus parallel (1) the fibres. Furthermore, this figure indicates a lincar behavior up to the ultmate load for the tensile test parallel to the filme direction.

These tests indicate clearly the highly anisotropic character of the unidirectional reinfored CFRP laminates, which show much higher strength in the fibre direction compared to the transverse direction. 


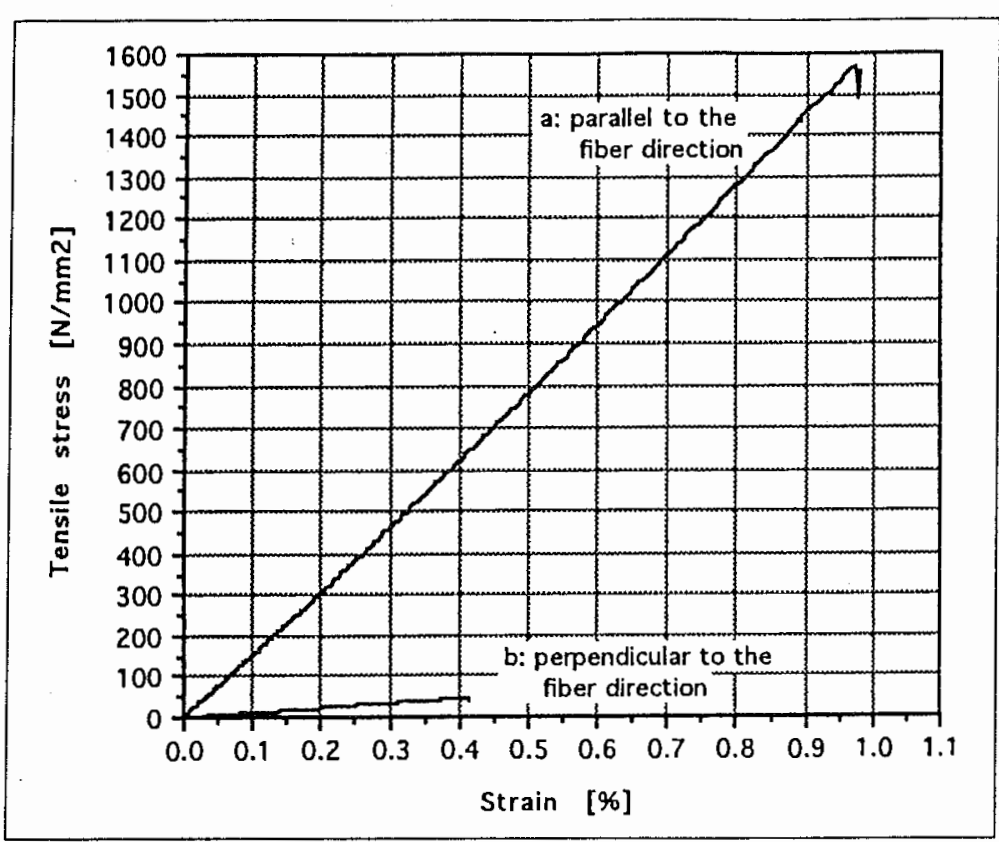

Fig. 2 - Tensile stress-strain curve of a unidirectional CFRP laminate: (a) parallel to the fibre direction (11), (b) perpendicular to the fibre direction (22). The laminate consists of T300 carbon fibres (Toray, Japan) and epoxy matrix (Ciba-Geigy, Switzerland). Tests resulted in $\mathrm{E} 11=158^{\prime} 550 \mathrm{~N} / \mathrm{mm}^{2}, \mathrm{E} 22=11^{\prime} 290 \mathrm{~N} / \mathrm{mm}^{2}$, $\sigma_{\mathrm{u} 11}=1^{\prime} 560 \mathrm{~N} / \mathrm{mm}^{2}$ and $\sigma_{\mathrm{u} 22}=46 \mathrm{~N} / \mathrm{mm}^{2}$.

\section{REFERENCES}

[1] Delmonte, J., 'Technology of Carbon and Graphite Fibre Composites' (Van Nostrand Reinhold Company, USA, 1981).

[2] Meier, U., Deuring, M., Meier, H. and Schwegler, G., 'Strengthening of structures with CFRP laminates: Research and applications in Switzerland', Canadian Society for Civil Eng. (1992) 243-252.

[3] Meier, U., 'Carbon fibre-reinforced polyners: modern materials in bridge engineering', Structural Eng. Int. 1/92 (1992) 7-11.
[4] Schwegler, G., 'Masonary construction strengthened with fibre composites in seismically endangered zones', Proceed. of $10 \mathrm{th}$ European conf. on Earthquake Eng., Austria, Vienna (1994).

[5] Motavalli, M., Terrasi, G. P. and Meier, U., 'On the behavior of hybrid aluminum/CFRP box beams at low temperatures', Composites Part A, 28A (1997) 121-129.

[6] Farshad, M., Wildenberg, M.W. and Flüeler, P., 'Determination of shear modulus and Poisson's ratio of polymers and foams by the anticlastic plate-bending method', Mater. Struct. 30 (20)(1) (1997) $377-382$. 